\title{
ACTUALIZACIONES
}

\section{Las moléculas de adhesión y la respuesta inmune}

\author{
Vergara C.I. ${ }^{1}$, Martínez B.M. ${ }^{2}$, Caraballo L.R. ${ }^{2}$
}

\begin{abstract}
Resumen
Las moléculas de adhesión (MA) participan en el reconocimiento antigénico y en la migración celular. Determinan el contacto entre varios grupos celulares y la relación entre algunas células y la matriz extracelular, actuando además como señales que contribuyen directamente a la activación celular. Con base en su estructura y características funcionales se pueden agrupar como: superfamilia de las inmunoglobulinas, las integrinas (que a su vez se subdividen en tres grupos: antígenos muy tardíos, integrinas leucocitarias y citoadhesinas) y las selectinas (E-selectinas, $P$-selectinas y L-selectinas). Su mecanismo de acción se ha estudiado en detalle en los procesos de migración leucocitaria que comprende: marginación por medio de selectinas, adhesión al endotelio y quimiotaxis a través de integrinas y, en menor grado, por miembros de la superfamilia de la inmunoglobulinas.
\end{abstract}

La manipulación de los procesos en los cuales intervienen estas moléculas, permitiría que en un futuro sean utilizados como terapia antiinflamatoria en medicina y biología.

\section{Summary}

Adhesion molecules (AM) are involved in antigenic recognition and cell migration. These molecules determine the contact among several groups of cells and the relationship between some cells and the extracellular matrix. In addition, they act as direct activation signals upon various immunocompetent cells. According to their structure and functional characteristics they have been grouped in: Inmunoglobulin superfamily, integrins (very late antigens, leukointegrins and cytoadhesins) and selectins (E-selectins, P-selectins $y$ L-selectins). Their mechanisms of action have been largel y studied in regard to the leukocyte migration process, which include: selectin-mediated margination; endothelial adhesion and chemotaxis involving integrins and in a less extent by the immunoglobulins superfamily members. The possibility exists that manipulation of important steps of these processes could be used in the future as therapeutic tools and basic research.

Las moléculas de adhesión (MA) determinan el contacto entre varios grupos celulares y la relación entre algunas células y la matriz extracelular, actuando además como señales que contribuyen directamente a la activación celular (1-6). Participan en diferentes etapas de la respuesta

1 Monitora, Instituto de Investigaciones Inmunológicas, Universidad de Cartagena.

2 Docentes, Instituto de Investigaciones Inmunológicas, Universidad de Cartagena. inmunológica y, aunque en un principio se consideraron accesorias, hoy se sabe que son esenciales para ciertas actividades de las células inmunocompetentes (7).

Dado que su estudio se inició recientemente, aún no se tiene una completa clasificación con base en su estructura y características funcionales. Sin embargo, teniendo en cuenta los hallazgos bioquímicos, se pueden agrupar convenientemente para facilitar su análisis en modelos experimentales y clínicos. En esta revisión se 
describirán las MA más estrechamente relacionadas con el sistema inmunológico con el fin de mostrar un resumen actualizado de sus características y posibles aplicaciones en medicina y biología.

\section{Moléculas de adhesión importantes en inmunología}

\section{Funciones}

Es bien conocido el papel de las MA en el traslado de los linfocitos de la médula ósea al timo, y en él, de la corteza a la médula (8); en las selecciones, positiva y negativa de ellos en este órgano (7) y en la migración de las células inmunocompetentes a los órganos linfáticos, a los sitios de inflamación y a los tejidos en general $(2,3,8-11)$. Esta circulación es permanente y no aleatoria, debido a que las células que se trasladan exponen en su membrana receptores (MA) cuyo contrarreceptor está localizado en el endotelio vascular y en los tejidos especializados, de manera que al acoplarse ambas estructuras cesa la circulación de las células portadoras.

Las MA son traductoras de señales que inducen directamente la activación celular $(4,5)$ durante la presentación antigénica y otros eventos, pero en ocasiones, dicha activación es posible también en ausencia de ellas; por este motivo se dice que son accesorias. El rápido aumento de la densidad de las MA en la superficie de las células estimuladas experimentalmente a través de anticuerpos dirigidos contra la molécula HLA$D R$, indica que también actúan como estabilizadoras y amplificadoras de uniones transitorias ya establecidas (12). En resumen, estos receptores tienen dos vías de acción: una, comunicar el medio extracelular con el intracelular y otra, regular las respuestas celulares adecuadas desde el interior hacia el medio externo.

\section{Localización}

Las MA se expresan sobre linfocitos, monocitos, células del endotelio vascular (en este sitio se expresan algunas veces como consecuencia de la liberación de citocinas), eosinófilos, neutrófilos, epitelio tímico, astrocitos y plaquetas, entre otras $(1,2,4,5,13)$. La mayoría de ellas se expresan en una gran variedad de células y la mayor parte de las células portan más de un tipo de MA. En general, las MA tienen baja afinidad en comparación con los receptores de los LT y LB. Establecen uniones entre células de una misma línea unión homotípica-por ejemplo, entre los linfocitos T y B mediante LFA-1 e ICAMs; y de diferentes líneas -unión heterotípica- como entre LT citotóxicos y células blanco (3).

\section{Clasificación}

De acuerdo con la similitud de sus características estructurales, las MA se han clasificado en diversos grupos. A continuación se describirán los de particular importancia en inmunología.

\section{A. Superfamilia de las inmunoglobulinas}

De esta familia, las moléculas mejor caracterizadas son los anticuerpos. Al igual que éstos, los otros miembros poseen cadenas polipeptídicas dispuestas en dominios que miden entre 90 y 100 aa cada uno. El número de dominios es variable a diferencia una molécula de otra. Estos receptores probablemente se originaron por duplicación genética y divergencia de una estructura sencilla primaria.

En esta familia (figura 1) se agrupan, además, los receptores $\mathrm{CD} 2, \mathrm{CD} 4, \mathrm{CD} 8, \mathrm{MHC}$, Igs, los antígenos funcionales leucocitarios (leukocyte funtional antigens) LFA-3 o CD58, las moléculas de adhesión intercelular (intercelular adhesion molecule) ICAMs, las MA de células vasculares (vascular cell adhesion molecule) VCAM-1 (CD106); de las plaquetas (platelet-endotelial cell adhesion molecule) PECAM y el receptor del linfocito $T$ (TCR).

EI CD2 es una de las moléculas mejor caracterizadas (14). Está relacionado con la línea linfoide e implicado en la interacción de los timocitos con las células del epitelio tímico a través del acople con su ligando, el LFA-3 $(4,15,16)$. Desempeña funciones en la señalización trasmembrana en asocio con el complejo TCR-CD3, produciendo un aumento de la respuesta de los linfocitos $T$ (LT) a antígenos específicos y estableciendo una unión más duradera. La activación a través del CD2 también parece afectar la adhesión mediada por integrinas, incrementando la avidez de LFA-1 y VLA (descritos más adelante) por sus respectivos ligandos (16). 


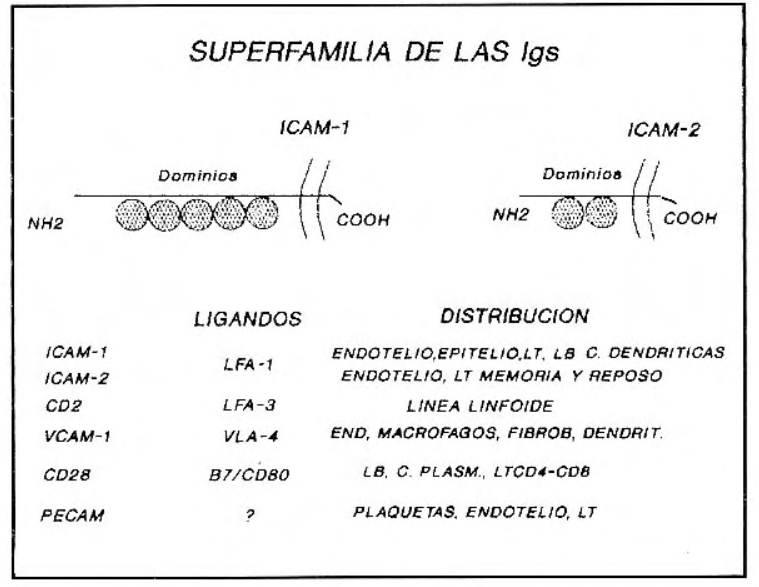

Figura 1. Estructura y distribución de las MA pertenecientes a la superfamilia de las inmunoglobulinas. Los círculos representan dominios de 90 a 100 aa cada uno, que se unen a las porciones trasmembranal e intra-citoplasmática.

La unión entre CD2 y el LFA-3 es independiente de la presencia de cationes divalentes, pero su avidez es condicionada por el estado de activación de los LT, los cuales en reposo no se adhieren a células $B$ o eritrocitos humanos que expresen LFA-3. Se necesitan de 12 a 24 horas para desarrollar las diferencias de avidez entre los LT en reposo y los activados $(4,16)$. Por su parte, las ICAMs desempeñan funciones críticas tanto en uniones heterotípicas como homotípicas. Tienen comoligando el LFA-1 (perteneciente a la familia de las integrinas) que se une indistintamente a los tres receptores ICAM descritos hasta ahora. Debido a los diferentes patrones de expresión de las ICAM, se piensa que cada una actúa para un propósito específico (17).

ICAM-1 tiene un peso molecular de $90 \mathrm{kd}$ y está codificada en el cromosoma 19. Posee 5 dominios extracelulares, una porción transmembrana y una porción intracitoplasmática. Se expresa en los leucocitos activados y células no linfoides que incluyen células epiteliales, endoteliales, fibroblastos, así como en las células dendríticas y centros germinales, lo cual sugiere que interviene en la diapédesis, facilitando la adherencia de LT a células de tejidos conectivos e incrementando la eficiencia de ciertas funciones de los LT (7).
De configuración muy parecida a la anterior, son los dominios de la molécula ICAM-2 (CD102) cuyo sitio de unión para el LFA-1 se encuentra entre los dominios I y II de la molécula en donde se conservan los residuos Glu 34, Gli 46, Gln 73 (en el dominio I), Asn 175 y Ser 177 (en el dominio II). Dichos residuos se encuentan también en la molécula ICAM-3 lo que confirma su estrecha relación $(3,17)$. Fawcet y col. (17) hallaron que la más alta expresión del RNAm que codifica esta molécula se da en las células implicadas en la presentación antigénica, probablemente en linfocitos B (LB) y células de la línea monocitomacrófago, aunque otros autores también afirman que esta molécula es propia del endotelio y ciertas células intersticiales (7).

Se piensa que la molécula de ICAM-3 (CD50) es la más importante (de las tres descritas) en la iniciación de la respuesta inmune, dado que es constitutivamente expresada en los leucocitos en reposo, en contraste con la baja expresión de la molécula ICAM-1 en estas células (17). Un importante papel de esta molécula se daría en la interacción leucocito-leucocito que se presenta antes de la regulación positiva de ICAM-1 durante la activación celular (3).

\section{B. Familia de las integrinas}

Es la familia mejor estudiada hasta hoy. Son consideradas como puentes entre el citoesqueleto y la matriz extracelular, aunque también median importantes eventos de adhesión intercelular $(4,7,14)$ reconociendo moléculas que pertenecen a la superfamilia de las inmunoglobulinas. Las integrinas tienen dos características intrínsecas:

1. capacidad de activación-inactivación; y,

2. señalización trasmembrana.

Están formadas por dos cadenas polipeptídicas, una pesada (180-200 kd) llamada alfa, con gran cantidad de residuos de azufre y sitios de unión para metales pesados y una liviana, beta, cuyo peso molecular es de 90 a $110 \mathrm{kd}$, con alto porcentaje de cisteínas $(4,14)$. Las dos cadenas están unidas en forma no covalente (figura 2) y se acoplan al contrarreceptor o ligando por la hendidura formada en la interfase de ellas (14). 


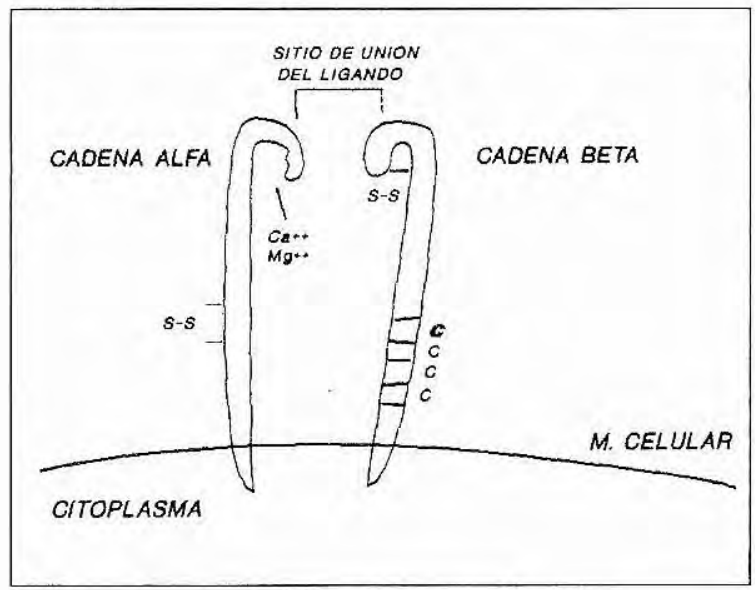

Figura 2. Esquema de una molécula de integrina, adaptado de la referencia 7.

Sus ligandos son elementos de la matriz extracelular especialmente laminina, vitrocectina y colágeno, a los cuales se unen por diferentes sitios donde se reconocen los residuos Arg-Gli-Asp (RGD).

A esta secuencia de reconocimiento, se pueden unir varias integrinas y si a esto se le suma el hecho de que una molécula de integrina se une a más de un ligando (14), se obtiene una diversidad de relaciones importantes para procesos como el desarrollo embrionario, hemostasis, trombosis, curación de heridas, mecanismos de defensa inmune y no inmune y mecanismos oncogénicos (7). Entre las integrinas hay alrededor de 20 heterodímeros descritos, conformados por cerca de 20 cadenas alfa y 8 cadenas beta y de acuerdo con sus características estructurales se ha subdividido en tres grupos:

1. Antígenos muy tardíos (very late antigens, $V L A$ ). A este grupo pertenecen la mayoría de las integrinas (tabla 1). Su nombre se debe a que aparecen en estados tardíos de la activación celular. Se han descrito 6 moléculas de VLA que se enumeran de la 1 a la 6 (CD49aCD49f). De igual forma, son miembros de ese grupo los receptores plaquetarios para colágeno GPla-lla y para fibronectina GPIc-Ila (18). La cadena beta de este grupo es la B1, sus contrareceptores son el VCAM-1 y la fibronectina, por medio de los cuales los leucocitos y plaquetas se adhieren a las células endoteliales y a la matriz extracelular (6).
Tabla 1. Antígenos muy tardíos (VLA). Clasificación y distribución.

VLA 9VERY LATE ANTIGENS)

\begin{tabular}{llll}
\hline C. ALFA & C. BETA & NOMBRE & LIGANDO \\
\hline ALFA 1 & BETA1 & VLA-1 & $\begin{array}{l}\text { Colágeno, } \\
\text { Laminina }\end{array}$ \\
ALFA 2 & BETA 1 & VLA-2 & $\begin{array}{l}\text { Colágeno, } \\
\text { Laminina }\end{array}$ \\
ALFA 3 & BETA 1 & VLA-3 & $\begin{array}{l}\text { Fibronectina } \\
\text { Laminina }\end{array}$ \\
ALFA 4 & BETA 1 & VLA-4 & $\begin{array}{l}\text { Fibronectina } \\
\text { VCAM-1 }\end{array}$ \\
ALFA 5 & BETA 1 & VLA-5 & Fibronectina \\
ALFA 6 & BETA 1 & VLA-6 & Laminina \\
\hline
\end{tabular}

Residuos de unión: Arg-Gli-Asp (RGD)

Distribución: leucocitos, plaquetas

2. Las integrinas leucocitarias (LEU-CAM). Son moléculas proadhesivas para la migración de neutrófilos (2) y LT (15) al tejido inflamado (tabla 2). Participan, así mismo, en la unión de los leucocitos a otras células (6). Dentro de este grupo, podemos citar al LFA-1 (CD18/ CD11a), Mac-1 (CD18/CD11b) y el P150, 95 (CD18/CD11c). Los dos últimos se expresan en la línea mieloide, LB y LT citotóxicos. Se piensa que los genes que codifican las cadenas alfa CD11b y CD11c provienen de un evento de duplicación genética (19). La cadena beta de estos receptores es la beta 2 y sus contrarreceptores son miembros de la superfamilia de las inmunoglobulinas.

3. Citoadhesinas (tabla 2). Este grupo de receptores está estrechamente relacionado con la adhesión de plaquetas y otras células al tejido conectivo, al igual que con la adhesión de neutrófilos al endotelio vascular (6). Dentro de los integrantes de este grupo está el CD61, el mayor receptor para el fibrinógeno (GPIIIla) que tiene en su estructura la cadena B3 de las integrinas.

Algunas personas padecen una enfermedad autosómica recesiva llamada LAD (leukocyte adhesion deficiency) que consiste en un defecto en los genes que codifican la cadena beta-2 de las integrinas con pérdida de su 
expresión y un produndo defecto en la adhesión. La salida de los PMN al espacio extravascular y el traslado de los mismos hacia el lugar de la inflamación, se dificulta porque en ellos estos pasos dependen de la presencia y funcionamiento de las beta-2 integrinas. En contraste, los linfocitos y eosinófilos no tienen sus funciones de adhesión alteradas porque éstas son ejecutadas por medio de las beta1 intregrinas $(4,13,20)$.

Otro aspecto en el que tiene repercusiones la deficiencia de integrinas es la maduración linfocítica. Se ha postulado que las células epiteliales tímicas y timocitos normales se unen a través del LFA-1 e ICAM-1; por tanto, en pacientes con $\angle A D$, la fijación de los linfocitos se daría sólo por medio del TCR y del MHC; esto hace suponer que sólo los que tienen gran afinidad por el MHC se van a unir, lo que puede dar origen a dos hechos: (1) demasiada apoptosis con los consiguientes problemas de inmunodeficiencia y/o (2) puede haber células de alta afinidad que escapen a la selección negativa y salgan al exterior presentando autorreactividad.

Tabla 2. Distribución de la integrinas leucocitarias y las citoadhesivas.

INTEGRINAS LEUCOCITARIAS (LEU-CAM)

\begin{tabular}{|c|c|c|c|}
\hline C. ALFA & C. BETA & NOMBRE & LIGANDO \\
\hline Alfa $L$ & Beta 2 & LFA-1 & ICAM1,2,3, \\
\hline Alfa M & Beta 2 & MAC-1 & $\begin{array}{l}\text { C3bi, fibrinógeno } \\
\text { factor } X, \text { ICAM-1 }\end{array}$ \\
\hline Alfa $X$ & Beta 2 & P150/95 & C3bi, fibrinógeno \\
\hline $\begin{array}{r}\text { Distribució } \\
\text { LFA } \\
\text { Neutró } \\
\text { Monoc } \\
\text { Granulo } \\
\text { LB Y } \\
\text { Precurs }\end{array}$ & $\begin{array}{l}n: \\
-1 \\
\text { filos } \\
\text { citos } \\
\text { ocitos } \\
\text { LT } \\
\text { sores }\end{array}$ & $\begin{array}{c}\text { MAC-1 } \\
\text { Granulocitos } \\
\text { Monocitos }\end{array}$ & $\begin{array}{c}\text { P150/95 } \\
\text { Monocitos } \\
\text { Macrófagos } \\
\text { Tisulares }\end{array}$ \\
\hline
\end{tabular}

CITOADHESINAS

\begin{tabular}{lll}
\hline Alfa llb Beta 3 & CD61 & Fibrinógeno \\
& Vitronectina \\
& Fibronectina
\end{tabular}

Distribución: plaquetas, neutrófilos

\section{Familia de las selectinas}

Las selectinas son un grupo de molécılas que regulan la unión de leucocitos al endotelio vascular (figura 3). Tienen una estructura característica común, conformada por: (a) un dominio $\mathrm{N}$ terminal con homología con las lectinas, de 117 a 120 aa, que le permite unirse con gran afinidad a los residuos de carbohidratos; (b) un dominio que es el factor de crecimiento epitelial y (c) una serie de secuencias repetitivas cortas, similares a las halladas en las proteínas de unión del complemento que se conectan a (d) una porción trasmembrana. En su extremo $\mathrm{C}$ terminal, posee una porción intracitoplasmática. Teniendo en cuenta estas características, a los miembros de esta familia se les ha dado el nombre genérico de lectin cell adhesion molecules (LECAM) $(4,6,11)$. Algunas de estas moléculas son constitutivas y otras son inducibles por la acción de interleucinas especialmente IL-1, IL-4, IL-5, FNT e INF gamma (21). Al igual que las integrinas, se han clasificado en varios subgrupos, descritos a continuación:

1. E-selectinas. Son moléculas de adhesión endotelial de los leucocitos (ELAM-1 o CD62E), expresadas transitoriamente por el endotelio cuando es activado por monocinas o trombina $(4,11)$.

2. P-selectinas. Dentro de este grupo están el CD62 (GMP-140) cuyo contrarreceptor es el CD15 (13), PAD-GEM que se encuentra muy tempranamente en las células del endotelio activadas por mediadores inflamatorios (histamina y trombina) y sobre plaquetas activadas (4). Hay evidencia que tanto las Eselectinas como las P-selectinas (CD62P) reconocen residuos sializados Lewis ${ }^{x}\left(s \mathrm{Le}^{\mathrm{x}} \mathrm{O}\right.$ $\mathrm{CD} 15 \mathrm{~s})$, un carbohidrato terminal que contiene ácido siálico y fucosa, hallado en los glucolípidos y glicoproteínas leucocitarias.

3. L-selectinas. Estas incluyen las moléculas LAM-1 (CD62L humano) o MEL-14 (ratón), LEU-8 y TQ-1. Recientemente se ha descrito un posible ligando para dichas moléculas llamado el GLYCAM-1, cuya actividad es dependiente de su sialación, fucosilación y sulfatación (15). 


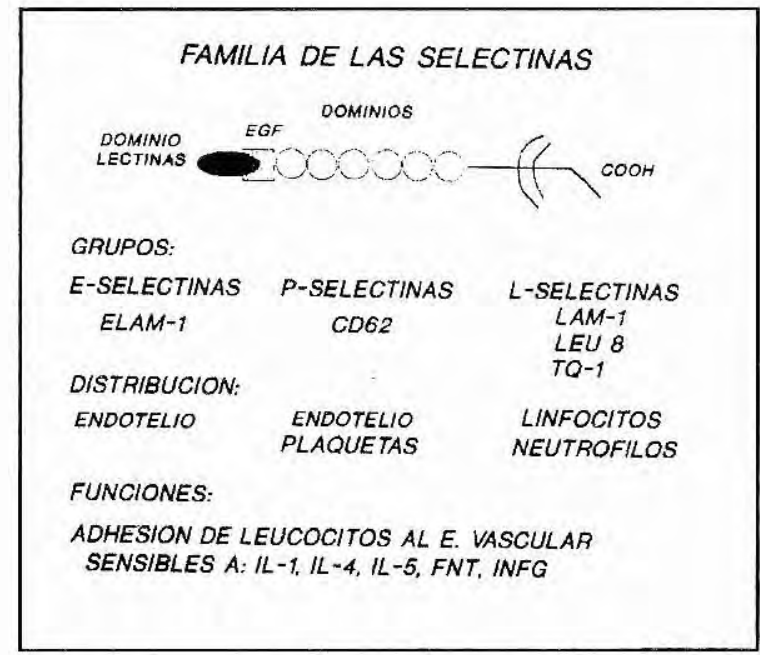

Figura 3. Estructura y clasificación de las selectinas.

\section{Mecanismo de acción}

Para comprender mejor la secuencia con que actúan las MA en la migración celular, es apropiado esbozar un modelo de activación y migración leucocitaria que se divide al menos en tres fases (figura 4):

1. Activación endotelial y expresión de selectinas. En este estado se liberan linfocinas tales como IL-1, FNT e IFN gamma, además de la histamina, la trombina, el factor activador de plaquetas PAF, que actúan como señal para la marginación leucocítica (6). Después de algunos minutos, las P-selectinas de la superficie de células endoteliales aumentan su afinidad por su contrarreceptor y las contenidas en los cuerpos de Weibel Palade se movilizan y expresan en la superficie, iniciándose la adhesión de neutrófilos y monocitos $(2,13)$. En el caso de linfocitos, la adhesión se da por la aparición de Ly E selectinas en su membrana y probablemente en la de otros leucocitos. La síntesis de E-selectinas es de novo y su expresión tarda aproximadamente una hora, es máxima a las 4-8 horas y los niveles regresan a los valores normales a las 24-48 horas $(2,13)$. Es de anotar que la fijación que se da en esta etapa es inestable, transitoria y reversible, está medida por el reconocimiento y unión de las selectinas a residuos SialylLewis ${ }^{\times}$sobre neutrófilos o linfocitos $(13,23)$.
Señales intracelulares mediadas por AMPc, $\mathrm{Ca}^{++}$, ácido araquidónico y enzimas tales como la proteincinasa, llevan a cambios tanto estructurales como funcionales, que permiten que se dé la expresión y la activación de los otros receptores involucrados en la migración (21). El fenómeno de marginación linfocítica se dé en forma más fácil a nivel de las vénulas postcapilares, ya que aquí se presenta baja volocidad de flujo sanguíneo, condición que favorece la estasis cirulatoria (5); además, la histamina promueve la vasodilatación permitiendo que circule una mayor cantidad de elementos celulares (21).

2. Incremento de las integrinas y enlace por medio de ellas. En este paso se establece una unión más estrecha. Las selectinas son elementos necesarios para la iniciación de la marginación, pero no son suficientes (14). Después de la activación de los leucocitos, se produce un cambio en la conformación de la estructura de las integrinas que hace que éstas se tornen más ávidas por su ligando. Posteriormente, aumenta su densidad a nivel de la membrana; en este paso también influyen los mediadores inflamatorios que per se producen activación de estas moléculas (14).

Se sabe que la transmisión de señales por medio de las integrinas, es un mecanismo iniciado por la fosforilación o unión a componentes citoplasmáticos (citoesqueleto u otros), aumento del $\mathrm{Ca}$ y del $\mathrm{pH}$ intracelular, tal vez por medio de la activación de una proteintirosincinasa de la familia src, que contribuyen a la activación de las células y a una mayor exposición de receptores de adhesión conformado un proceso de retroalimentación positiva (14).

3. Fuerte adhesion mediada por las integrinas. Después que se produce la unión integrinaligando, se estabiliza. Pero, para que se inicie, es necesario la activación. Igual importancia tiene la reversión de la unión para evitar consecuencias anómalas como la trombosis o la inflamación. Se piensa que aquí también interviene la fosforilación $(14,23)$. 


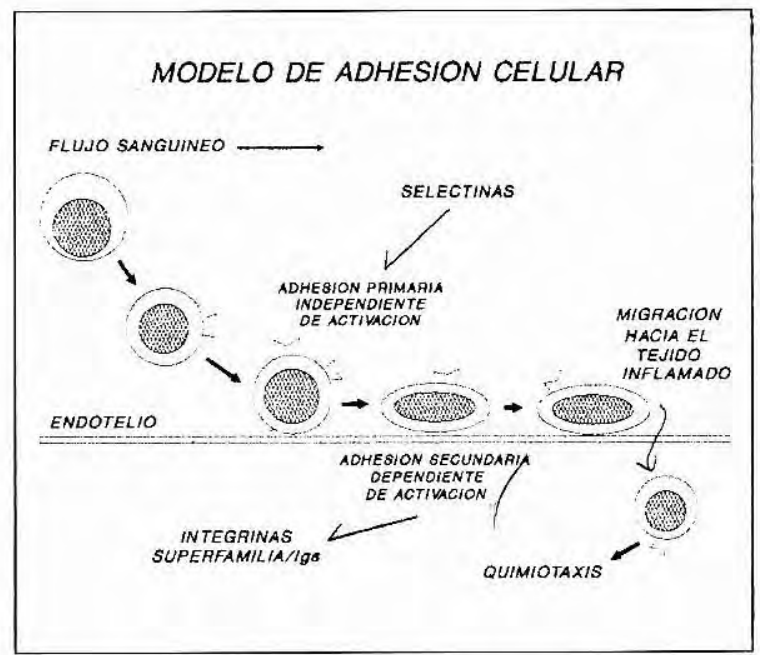

Figura 4. Secuencia de eventos durante la adhesión y migración celular.

\section{Conclusiones e implicaciones clínicas}

En conclusión, las integrinas trasmiten señales desde afuera para informar a la célula acerca de su medio externo y actúan también desde el medio interno para que la célula responda adecuadamente a las exigencias del medio externo. En los procesos inflamatorios, son de particular importancia porque permiten la salidad de los elementos celulares de los vasos sanguíneos y la continuación de su traslado a través del espacio extravascular, en el cual intervienen los receptores para fibrinógeno, fibronectina y ácido hialurónico que permiten su llegada hasta el lugar de la injuria o invasión (13).

Clínicamente han sido reconocidas algunas MA como el ICAM-1, que actúa como receptor para Plasmodium falciparum en su estado infeccioso y para rinovirus $(4,6)$. De forma similar, algunas selectinas producidas por E. colison específicas para ciertos carbohidratos y pueden permitir su adhesión al endotelio afectado. Se piensa que esta unión es el primer paso en el inicio de la infección (24). Sin embargo, como se ha descrito en esta revisión, existen numerosas moléculas de adhesión que determinan el curso de la respuesta inmunológica, tanto en condiciones normales como en procesos patológicos.

Recientes descubrimientos en los receptores de superficie, indican la presencia de MA en molé- culas tumorales donde incrementarían su capacidad para producir metástasis. En este campo ha sido implicada otra familia de MA, denominadas caderinas, receptores de la familia de las integrinas y a variaciones del CD44 (receptor para el ácido hialurónico) (25).

De lo anterior se deduce que las moléculas de adhesión intervienen en diversos procesos. Manipulando algunos de ellos, se pueden obtener esquemas susceptibles de emplear como terapia antiinflamatoria (26). Aunque es mucho lo que se conoce de este tema, todavía hay mecanismos que permanecen indefinidos.

\section{Referencias}

1. Mantovani A, Dejana E. Cytokines as communication signals between leukocytes and endothelial cells. Inmunol Today 1989; 10:370.

2. Zimmerman GA, Prescott S, McIntyre T. Endothelial cells interactions with granulocytes: tethering and signaling molecules. Immunol Today 1992; 13:93.

3. Vazeux R, Hoffman P, Tomita J, et al. Cloning and characterization of a new intercellular adhesion molecule ICAM-R. Nature 1992; 360:485.

4. Dustin M, Springer T. Role of lymphocyte adhesion receptors in transient interactions and cell locomotion. Annu Rev Immunol 1991; 9:27.

5. Shimizu Y, Newman W, Tanaka Y, et al. Lymphocyte interactions with endothelial cells. Immunol Today 1992; 13:106.

6. Sutherland, D. The molecular basis of the allergic response: a new challenge for clinicians. All Clin Immunol News 1992: 4:180.

7. Shevach E. Accesory molecules. Chapter 15, in Paul W. Fundamental Immunology, third ed. New York: Raven Press Ltd., 1993:531.

8. Kaye J, Ellenberger D. Differentiation of an immature T cell line: a model of thymic positive selection. Cell 1992; 71:423.

9. Watson S, Fennie C, Lasky L, et al. Neutrophil influx into an inflammatory site inhibited by a soluble homing receptor-IgG chimaera. Nature 1991; 349:164.

10. Dowbenko D, Diep A, Taylor B, et al. Characterization of the murine homing receptor gene reveals correspondence between proteins domains and coding exons. Genomics 1991; 9:270.

11. Lasky L. Lectin cell adhesion molecules (LEICAMs): a new family of cell adhesion proteins involved with inflammation. J Cell Biochem 1991; 45:139.

12. Odum N, Yoshizumi H, Okamoto $Y$, et al. Signal transduction by class II molecules in human $T$ cells: induction of LFA-1 dependent and independent adhesion. Hum immunol 1992; 35:71. 
13. Hansel T, Walker C. The migration of eosinophils into the sputum of asthmatics: the role of adhesion molecules. Clin Exp Allergy 1992; 22:345.

14. Jones E, Davis S, Williams A, et al. Crystal structure al 2.8. A resolution of a soluble form of the cell adhesion molecule CD2. Nature 1992; 360:232.

15. Mackay $\mathrm{Ch}$, Imhof B. Cell adhesion in the immune sistem. Immunol Today 1993: 14:99.

16. van Seventer G, Shimizu Y, Shaw S. Roles of multiple accesory molecules in T cell activation. Curr Opin Immunol 1991; 3:294.

17. Fawcett J, Holness C, Needham L, et al. Molecular cloning of ICAM-3, a third ligand for LFA-1, constitutively expressed on resting leukocytes. Nature 1992; 360:481.

18. Roth G. Platelets and blood vessels: the adhesion event. Immunol Today 1992; 13:100.

19. Fleming J, PahI H, González D, et al. Structural analysis of the CD11b gene and phylogenetic analysis of the alfa integrin gene family demostrate remarkable conservation of genomic organization and suggest early diversification during evolution. J Immunol 1993; 150:480.
20. Harlan J. Mechanisms and consecuences of leukocyte adherence to endothelium in the vascular endothelium: understanding its role in inflammation. Postgraduate education course and asthma consultant's course syllabus 1993; 158.

21. Calderón E, Lockey R. A possible role for adhesion molecules in asthma. All Clin Immunol 1992; 90:852.

22. Hynes R. Integrins: versatility, modulation and signaling in cell adhesion. Cell 1992; 69:11.

23. Butcher E. Leukocyte-endothelial cell recognition: three (or more) steps to specificity and diversity. Cell 1991;67: 1033.

24. Sharon N, Lis $\mathbf{H}$. Carbohydrates in cell recognition. Scientific American 1993; 268:74.

25. Herrlich P, Zoller M, Pals S, et al. CD44 splice variants: metastases meet lymphocytes. Immunol Today 1993; 14:395.

26. Mulligan M, Paulson J, De Feest $\mathbf{S}$, et al. Protective effects of oligosaccharides in P-selectin-dependent injury. Nature 1993; 364:652. 